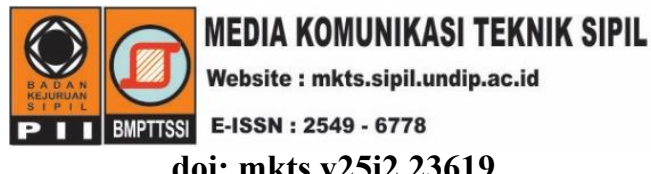

doi: mkts.v25i2.23619

\title{
Mitigasi Non Revenue Water (NRW) Sistem Jaringan Distribusi pada District Meter Area (DMA) Zona Kota Blahbatuh PDAM Gianyar
}

\author{
"Mawiti Infantri Yekti, Ida Bagus Gede Pebriarta Pratama, Ida Bagus Ngurah Purbawijaya \\ Program Studi Teknik Sipil, Fakultas Teknik, Universitas Udayana, Denpasar \\ ${ }^{*}$ wiwiet91@yahoo.com
}

Received: 13 Juni 2019 Revised: 16 Desember 2019. Accepted: 20 Desember 2019

\begin{abstract}
The most common problem with drinking water supply is Non Revenue Water (NRW). NRW can be grouped into two types, namely physical water loss and non-physical water loss. This study aims to determine the NRW size, NRW causes, counter measures that can be done to suppress NRW. The results of evaluation of distribution networks that occur in the Blahbatuh City Zone District Meter Area (DMA) PDAM Gianyar. The difference between the amount of water distributed and the amount of water recorded in the account is NRW. The way to find out the cause and control of NRW is to analyze the results of the step test, UFM test (Ultrasonic Flow Meter), and conduct the interviews with employees of PDAM. The evaluation of distribution networks is only done in DMA Pande that has completed data. The amount of NRW that occured in the Blahbatuh City Zone is 474,142.83 $\mathrm{m}^{3} /$ year (59.91\%). The water loss is caused by damage to pipe accessories, leaky pipes, inaccuracies in the accuracy of the water meter. The water loss can be overcame by establishing a DMA, replacing pipe accessories, calibrating and replacing water meters. The evaluation results for the existing conditions of the distribution network in DMA Pande of Blahbatuh City Zone have not worked optimally. It seen from the results of the waternet and from the number of SR's that have not met the requirements for the formation of a DMA.
\end{abstract}

Keywords: Non revenue water, district meter area, causes, mitigation, evaluation

\begin{abstract}
Abstrak
Permasalahan penyediaan air minum yang paling sering terjadi adalah Air Tidak Berekening (NRW). NRW dapat dikelompokkan menjadi dua jenis yaitu kehilangan air fisik dan kehilangan air non fisik. Penelitian ini bertujuan untuk mengetahui besarnya NRW, penyebab NRW, penanggulangan yang dapat dilakukan untuk menekan NRW, dan hasil evaluasi jaringan distribusi yang terjadi di dalam District Meter Area (DMA) Zona Kota Blahbatuh PDAM Gianyar. Selisih antara jumlah air yang didistribusikan dengan jumlah air yang tercatat di rekening disebut NRW. Cara yang dilakukan untuk mengetahui penyebab dan penanggulangan NRW adalah dengan menganalisis hasil langkah penapisan (step test), uji Pengukur Aliran Ultrasonik/UFM (Ultrasonic Flow Meter), serta melakukan wawancara dengan pegawai PDAM. Evaluasi jaringan distribusi hanya dilakukan di DMA Pande yang memiliki data lengkap. Besarnya NRW yang terjadi di Zona Kota Blahbatuh adalah sebesar 474.142,83 $\mathrm{m}^{3} /$ tahun (59,91\%). Kehilangan air disebabkan oleh rusaknya aksesoris pipa, pipa bocor, ketidakakuratan akurasi water meter. Kehilangan air dapat ditanggulangi dengan melakukan pembentukan DMA, penggantian aksesoris pipa, melakukan kalibrasi dan penggantian water meter. Hasil evaluasi untuk kondisi eksisting jaringan distribusi di DMA Pande belum bekerja secara optimal. Hal itu dilihat dari hasil waternet dan dari jumlah SR yang belum memenuhi syarat terbentuknya suatu DMA.
\end{abstract}

Kata Kunci: Air tidak berekening, kawasan bermeter, penyebab, penanggulangan, evaluasi 


\section{Pendahuluan}

Air merupakan kebutuhan yang sangat vital bagi kehidupan manusia. Salah satu kebutuhan hidup yang utama yaitu kebutuhan air bersih. Maka dari itu, pada setiap daerah terdapat Perusahaan Daerah Air Minum (PDAM) yang memberikan pelayanan air bersih kepada masyarakat. Masalah yang paling besar dan selalu terjadi dalam pengelolaan air minum adalah kehilangan air atau Air Tidak Berekening (Non Revenue Waterl NRW). NRW merupakan selisih antara volume input sistem dan konsumsi resmi berekening (Putra, 2009). Berdasarkan bentuknya, kehilangan air dapat dibedakan menjadi dua yaitu kehilangan air non fisik dan kehilangan air fisik.

Salah satu upaya yang dapat dilakukan untuk menekan tingkat kehilangan air fisik adalah dengan pembentukan kawasan bermeter (DMA). Hal tersebut berarti suatu DMA adalah suatu wilayah atau area yang dibatasi oleh satu atau beberapa meter air (Annisa \& Hadi, 2015).

Penanganan kehilangan air non fisik dapat ditempuh dengan melakukan tindakan srategis baik melalui sektor administratif maupun hukum, antara lain dengan menetapkan peraturan untuk memberikan sanksi kepada pencuri air dan sambungan ilegal, melakukan kalibrasi meter air induk dan meter air pelanggan, melakukan penggantian meter air pelanggan secara berkala (dua atau lima tahun sekali), melakukan pemeriksaan ulang untuk membaca meter air pelanggan, hingga melakukan inspeksi mendadak untuk pelanggan skala besar.

Menurut BPPSPAM (Badan Peningkatan Penyelenggaraan Sistem Penyediaan Air Minum) tahun 2014, ada sebanyak 38,4\% air yang diproduksi oleh PDAM di Indonesia hilang sehingga tidak terbayarkan. Hal ini menyebabkan kerugian sebesar Rp. 1,139 Triliun setiap tahunnya. Kehilangan air ini terdiri dari konsumsi resmi tak berekening 1,9\%, kehilangan air komersial 11,5\% dan kehilangan air fisik $25 \%$.

Berdasarkan data Laporan Teknik PDAM Gianyar tahun 2018, PDAM Gianyar terdiri dari tujuh cabang yang terbagi atas 51 zona yaitu Tampaksiring (delapan zona), Tegalalang (empat zona), Payangan (lima zona), Ubud (delapan zona), Sukawati (lima zona), Blahbatuh (tujuh zona), dan Gianyar (14 zona).

Pada Zona Blahbatuh terdapat tujuh zona salah satunya adalah zona Kota Blahbatuh dengan memiliki NRW paling tinggi. Di zona ini memiliki tiga buah DMA dengan total tingkat NRW yang cukup tinggi setiap bulannya. Adapun besarnya NRW dari bulan Januari 2017 hingga bulan Desember 2017 adalah sebesar 58,6\%; 50,9\%; $48,14 \%$; 62,29\%; 52,88\%; 63,59\%; 57,26\%; $67,69 \% ; 65,71 \% ; 63,67 \%$; 64,49\%; $57,99 \%$, dengan rata-rata sebesar $59,44 \%$.

Berdasarkan hal tersebut di atas, maka perlu dilakukan suatu analisis NRW dalam DMA zona Kota Blahbatuh PDAM Gianyar, khususnya di DMA Pande yang memiliki data lengkap untuk mengetahui besarnya NRW dan penyebabnya serta mencari solusi untuk masalah yang terjadi.

\section{Sistem penyediaan air minum}

Berdasarkan PP Nomor 122 Tahun 2015 tentang Sistem Penyediaan Air Minum (KEMENTRIANPUPR, 2016). Sistem Penyediaan Air Minum adalah kegiatan menyediakan air minum untuk memenuhi kebutuhan masyarakat agar mendapatkan kehidupan yang sehat, bersih, dan produktif. Sistem penyediaan air minum yang selanjutnya disebut SPAM merupakan satu kesatuan sistem fisik dan non fisik dari prasarana dan sarana air minum.

\section{Air tidak berekening (NRW)}

Berdasarkan Peraturan Menteri Pekerjaan Umum Nomor 20 Tahun 2006 tentang batas maksimal kebocoran air bersih untuk perusahaan air minum, toleransi NRW maksimal adalah sebesar $20 \%$. NRW adalah selisih antara jumlah air yang diproduksi dengan air yang terjual atau yang didistribusikan kepada pelanggan melalui meter air. NRW juga merupakan suatu indikator yang menunjukkan kinerja dari manajemen air, semakin tinggi nilai NRW mengindikasikan buruknya manajemen yang dilakukan (Frauendorfer \& Liemberger, 2010).

\section{Penyebab kehilangan air}

Penyebab kehilangan air dapat dibagi menjadi dua yaitu kehilangan air fisik dan kehilangan air non fisik. Kehilangan air fisik adalah kehilangan air yang secara nyata terbuang dari sistem distribusi sehingga tidak dapat dimanfaatkan. Kehilangan air ini umumnya dapat terlihat secara fisik misalnya dengan adanya aliran air yang keluar dari jaringan pipa distribusi (Febriany, 2014).

Menurut Farley et al. (2008) kehilangan air non fisik merupakan hilangnya air yang terjadi dan secara fisik tidak terlihat atau tidak diperhitungkan dalam proses penagihan. Kehilangan air ini dapat berupa kehilangan air tercatat maupun tidak tercatat. 


\section{Kerugian akibat kehilangan air}

Secara garis besar kerugian akibat kehilangan air dapat dikelompokkan menjadi enam yaitu Kerugian terhadap kuantitas air, kerugian kualitas air, Kerugian terhadap kontinuitas, Kerugian dari segi keuangan, Kerugian terhadap faktor sosial, Kerugian terhadap lingkungan. (Tanjung, 2013).

\section{Kawasan bermeter (DMA)}

Kawasan Bermeter (DMA) merupakan suatu cara penurunan kehilangan air dengan cara membagi satu jaringan pasokan air menjadi zona-zona kawasan bermeter. DMA bertujuan untuk mendeteksi suatu kebocaran pada suatu bagian sistem jaringan distribusi yang difokuskan menjadi satu wilayah deteksi kebocoran. Dengan kata lain, suatu daerah jaringan distribusi diisolasi untuk melihat potensi terjadinya kebocoran di daerah tersebut.

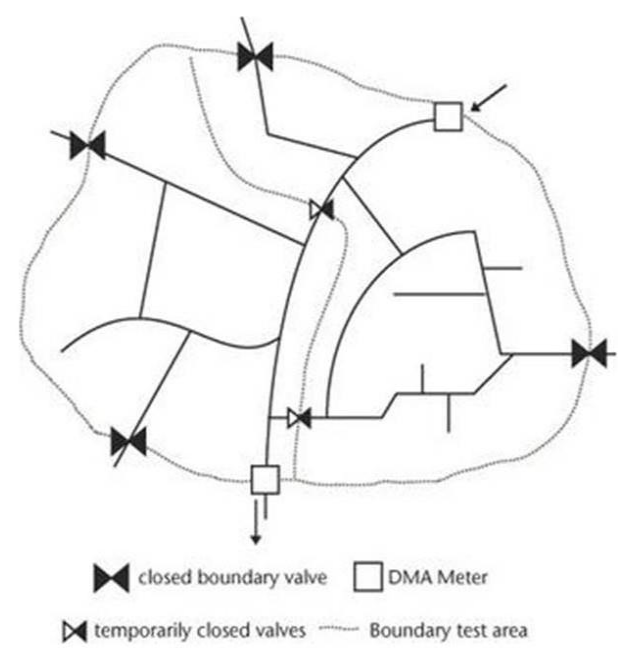

Gambar 1. District meter area

Menurut (Farley et al., 2008), Kriteria rancangan DMA harus benar-benar diperhatikan untuk mengahasilkan sistem yang efektif. Kriteria tersebut antara lain yaitu jumlah sambungan pada DMA umumnya antara 1000-2500 sambungan, jumlah katup yang harus ditutup untuk mengisolasi DMA, banyaknya meter air untuk mengukur air masuk dan air keluar (semakin sedikit meter yang diperlukan, semakin kecil biaya pembentukan), variasi permukaan tanah yang berpengaruh terhadap tekanan di dalam DMA (semakin datar kawasan, semakin stabil tekanan yang ada sehingga lebih mudah untuk membentuk kendali tekanan).

\section{Neraca air}

Neraca air merupakan suatu gambaran hubungan antara inflow (aliran masuk) dengan outflow (aliran keluar) pada suatu wilayah selama periode tertentu. Pada sistem penyediaan air minum, neraca air digunakan sebagai alat untuk menghitung kehilangan air yang nantinya digunakan untuk mengontrol sehat tidaknya sistem (Rinaldi, 2016).

Neraca air merupakan metode perhitungan kehilangan air yang diusulkan oleh The International Water Association (IWA) pada tahun 2001 di Berlin. Berdasarkan tabel di atas, dapat didefinisikan yaitu air tak berekening (NRW) sebagai selisih antara volume input total pada sistem dengan konsumsi berekening.

Tabel 1. Neraca air internasional

\begin{tabular}{|c|c|c|c|c|}
\hline & \multirow{2}{*}{$\begin{array}{l}\text { Konsumsi } \\
\text { resmi }\end{array}$} & $\begin{array}{l}\text { Konsumsi } \\
\text { resmi } \\
\text { berekening }\end{array}$ & $\begin{array}{c}\begin{array}{c}\text { Konsumsi } \\
\text { bermeter } \\
\text { berekening }\end{array} \\
\begin{array}{c}\text { Konsumsi tak } \\
\text { bermeter } \\
\text { berekening }\end{array}\end{array}$ & $\begin{array}{c}\text { Air } \\
\text { berekening }\end{array}$ \\
\hline & & $\begin{array}{l}\text { Konsumsi } \\
\text { resmi tak } \\
\text { berekening }\end{array}$ & $\begin{array}{c}\begin{array}{c}\text { Konsumsi } \\
\text { bermeter tak } \\
\text { berekening }\end{array} \\
\begin{array}{c}\text { Konsumsi tak } \\
\text { bermeter tak } \\
\text { berekening }\end{array}\end{array}$ & \multirow{4}{*}{$\begin{array}{c}\text { Air Tak } \\
\text { berekening } \\
\text { (NRW) }\end{array}$} \\
\hline & \multirow[b]{3}{*}{$\begin{array}{c}\text { Kehilangan } \\
\text { air }\end{array}$} & & $\begin{array}{c}\text { Konsumsi tak } \\
\text { resmi }\end{array}$ & \\
\hline \multirow[t]{2}{*}{$\begin{array}{l}\text { Volume } \\
\text { input } \\
\text { system }\end{array}$} & & $\begin{array}{c}\text { Kehilangan air } \\
\text { non fisik }\end{array}$ & $\begin{array}{l}\text { Ketidakakuratan } \\
\text { meter pelanggan } \\
\text { dan kesalahan } \\
\text { penanganan data }\end{array}$ & \\
\hline & & $\begin{array}{l}\text { Kehilangan air } \\
\text { fisik }\end{array}$ & $\begin{array}{c}\text { Kebocoran pada } \\
\text { pipa distribusi dan } \\
\text { transmisi } \\
\text { Kebocoran dan } \\
\text { luapan dari tangki- } \\
\text { tangki } \\
\text { penyimpanan } \\
\text { penyediaan air } \\
\text { minum } \\
\text { Kebocoran di pipa } \\
\text { dinas hingga ke } \\
\text { meter pelanggan } \\
\end{array}$ & \\
\hline
\end{tabular}

Adapun komponen NRW dapat dihitung dengan persamaan sebagai berikut:

$\mathrm{NRW}=$ Volume Input Sistem -

Konsumsi Berekening

dimana NRW merupakan Non Revenue Water (air tak berekening)

\section{Menghitung kehilangan air}

Secara umum, perhitungan untuk mencari persen kehilangan air dapat menggunakan rumus sebagai berikut:

$\mathrm{H}=\frac{(D-K)}{D} x 100 \%$

Dimana $\mathrm{H}$ merupakan kehilangan air (\%), D merupakan jumlah air yang didistribusikan $\left(\mathrm{m}^{3}\right), \mathrm{K}$ merupakan jumlah air yang terjual atau jumlah air yang tercatat dalam rekening tagihan $\left(\mathrm{m}^{3}\right)$ (Sembiring, 2017). 


\section{Menanggulangi kehilangan air fisik}

Penanganan kehilangan air fisik memerlukan pemahaman terhadap permasalahan dan perlu komitmen yang kuat dari manajemen PDAM, karena upaya penurunan kehilangan air merupakan upaya jangka panjang. Strategi komunikasi penurunan kehilangan air harus dilakukan untuk mendapatkan dukungan dari pengambil keputusan seperti politisi (legislative), dan otoritas keuangan (penyandang dana) dari Kementrian Pekerjaan Umum.

Dalam penanganan kehilangan air fisik, dikenal empat strategi, seperti terlihat pada gambar berikut.

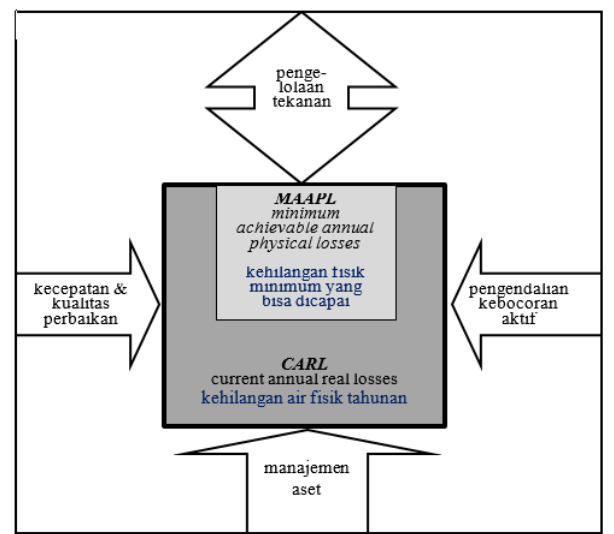

Gambar 2. Strategi penanganan kehilangan air fisik

Berdasarkan gambar di atas, konsep strategi penanganan kehilangan air fisik dapat berupa kecepatan dan kualitas perbaikan, pengendalian kebocoran aktif, manajemen asset, dan pengelolaan tekanan. Apabila strategi penganan tersebut dilakukan dengan baik tentu akan mampu menekan kehilangan air fisik.

\section{Menanggulangi kehilangan air non fisik}

Strategi pengendalian kehilangan air non fisik pada distribusi air bersih merupakan hal yang lebih mudah dilaksanakan jika dibandingkan dengan mengurangi kehilangan fisik karena tidak perlu melakukan penanggulangan secara teknis. Kegiatan yang dapat dilakukan untuk menanggulangi kehilangan air non fisik antara lain yaitu penertiban sambungan ilegal atau konsumsi yang tidak sah, penanganan audit akurasi meter pelanggan, penanganan ketelitian pembacaan meter dan transfer data untuk penagihan (Imsawan el-Ahmady \& Sembiring, 2014).

\section{Water net}

WaterNet merupakan sebuah program yang dirancang untuk melakukan simulasi aliran air atau fluida lainnya dalam pipa baik dengan jaringan tertutup (loop) maupun jaringan terbuka dan sistem pengaliran fluida dapat menggunakan sistem gravitasi, sistem pompanisasi maupun keduanya (Syahputra, 2015). WaterNet dirancang untuk memberikan banyak kemudahan sehingga pengguna dengan pengetahuan minimal tentang jaringan distribusi dapat menggunakannya juga.

\section{Langkah penapisan (step test)}

Langkah penapisan (step test) merupakan suatu metode yang diterapkan sebagai (scoping) jaringan dalam upaya mempersempit wilayah cakupan aliran air, untuk memperkirakan lokasi dan besarnya kebocoran. Step test dilakukan mulai dari wilayah terkecil yakni sub zona. Step test diperlukan untuk menentukan prioritas pengawasan jaringan terhadap kebocoran.

\section{Metode Penelitian}

Penelitian yang dilakukan berlokasi pada daerah yang bertempat di salah satu zona layanan PDAM Gianyar yaitu Zona Kota Blahbatuh. Populasi pada zona ini adalah sebesar 1574 SR. Pada daerah layanan Zona Kota Blahbatuh PDAM Kabupaten Gianyar menggunakan sistem jaringan distribusi berupa sistem cabang terbuka.

Sistem ini berarti saat memasuki DMA, pipa pelayanan yang digunakan tidak membentuk loop atau mengelilingi suatu sistem sehingga mempunyai akhir atau ujung. Pada Zona Kota Blahbatuh air yang didistribusikan merupakan air yang berasal dari reservoir Wanayu dengan volume $400 \mathrm{~m}^{3}$. Volume air tersebut terdistribusi menuju Zona Bedulu kemudian menuju Zona Kota Blahbatuh dengan tambahan dua buah Sumur Bor Buruan.

Pengumpulan data dilakukan dengan beberapa cara yaitu berupa studi literatur, pengambilan data primer dan data sekunder. Tahapan pengumpulan data yang dilakukan antara lain studi literatur atau tinjauan kepustakaan dilakukan bertujuan untuk memperoleh data berupa rumus ataupun dasar teori yang mendukung penelitian. Sudi literatur diperoleh dari berbagai sumber seperti buku, internet, jurnal, dan lainnya. Data primer yaitu berupa data yang didapatkan secara langsung saat melakukan observasi di lapangan. Adapun data yang diperlukan adalah tekanan dan akurasi meter. Data sekunder adalah data yang diperoleh secara tidak langsung dari PDAM Gianyar. Data sekunder yang digunakan antara lain yaitu hasil step test dan uji Ultrasinic Flow Meter (UFM), kondisi eksisting, peta jaringan distribusi, panjang pipa, jumlah air yang didistribusi, jumlah sambungan pelanggan, 
dan jumlah air di rekening tagihan. Langkah selanjutnya yaitu pemecahan masalah berupa pengolahan data dan analisis. Hasil pengolahan data dan analisis selanjutnya dibahas sesuai dengan hasil dan literatur. Pengolahan dan analisis data pada penelitian ini yaitu sebagai berikut:

\section{Perhitungan NRW.}

Perhitungan ini dilakukan untuk melihat persen NRW yang terjadi dalam suatu kawasan bermeter (DMA) apakah melebihi batas maksimum yang diijinkan berdasarkan Peraturan Menteri Pekerjaan Umum Nomor 20 Tahun 2006 yaitu sebesar $20 \%$. Seandainya hasil yang didapat melebihi batas maksimum yang diijinkan maka dapat diberikan rekomendasi upaya pengendalian air.

\section{Penyusunan neraca air}

Salah satu metode yang digunakan untuk mengetahui nilai kehilangan air yaitu dengan penyusunan neraca air. Data yang diperlukan untuk menghitung neraca air meliputi ketidak akuratan meter pelanggan, volume input, konsumsi resmi, kehilangan air, kehilangan fisik dan non-fisik.

\section{Analisis penyebab dan peanggulangan NRW}

Dengan menganalisis data hasil step test dan data hasil uji UFM serta hasil pengamatan di lapangan diharapkan dapat mengetahui penyebab dan penanggulangan NRW yang terjadi.

\section{Evaluasi jaringan distribusi}

Pada jaringan distribusi DMA Zona Kota Blahbatuh akan dilakukan suatu evaluasi untuk memperoleh rekomendasi upaya pengendalian air. Evaluasi ini dilakukan dengan menggunakan aplikasi WaterNet berdasarkan data sekunder yang diperoleh dari PDAM Gianyar.

\section{Hasil dan Pembahasan}

\section{Menghitung air tidak berekening (NRW)}

Berdasarkan data laporan teknik PDAM Gianyar bulan Januari hingga Desember 2018 dapat dihitung besarnya volume air yang didistribusikan dan dikonsumsi Zona Kota Blahbatuh. Data air yang didistribusikan dan dikonsumsi Zona Kota Blahbatuh dapat dilihat pada Tabel 2. Berdasarkan data distribusi dan konsumsi air di atas, maka besarnya NRW dan tingkat kehilangan air di Zona Kota Blahbatuh pada tahun 2018 dapat dihitung sebagai berikut:

$$
\begin{aligned}
\text { NRW } & =\text { Volume input system }- \text { Konsumsi berekening } \\
& =65.954,49-26.442,58 \\
& =39.511,9 \mathrm{~m}^{3} / \text { tahun } \\
& =474.142,83 \mathrm{~m}^{3} / \text { tahun }
\end{aligned}
$$

Besarnya NRW dalam persen dapat dihitung sebagai berikut:

$$
\begin{aligned}
\text { NRW }(\%)= & \frac{(\text { Vol input system }- \text { Konsumsi berekening })}{\text { Vol input system }} \times 100 \% \\
& =\frac{(65.954,49-26.442,58)}{65.954,49} \times 100 \% \\
& =59,91 \%
\end{aligned}
$$

Berdasarkan hasil perhitungan di atas, besarnya NRW di Zona Kota Blahbatuh pada tahun 2018 adalah sebesar 39.511,9 $\mathrm{m}^{3} /$ bulan atau sebesar $59,91 \%$ dari volume air yang didistribusikan. Persentase NRW yang terjadi di Zona Kota Blahbatuh jauh melebihi batas yang diijinkan yaitu sebesar $20 \%$ dari air yang didistribusikan. Hal ini menunjukan bahwa NRW di Zona tersebut tergolong tinggi karena air yang hilang lebih dari $50 \%$ air yang terdistribusi. Oleh karena itu, perlu dilakukan tindakan-tindakan untuk menekan kehilangan air sehingga kerugian yang diakibatkan dapat diminimalisir.

\section{Pengukuran akurasi water meter}

Pengukuran akurasi water meter pelanggan bertujuan untuk mengetahui ketelitian meter air pelanggan di Zona Kota Blahbatuh. Pengambilan sampel dilakukan pada water meter pelanggan di ruas pipa yang memiliki tingkat kehilangan air tertinggi pada saat dilakukan step test yaitu pada ruas pipa yang dibatasi oleh V16, V17, V18, V19 dan V22.

Hasil survei yang telah dilakukan dapat dilihat pada Tabel 3. Ketidakakuratan water meter dapat dihitung dengan rumus:

$$
\begin{aligned}
& \text { Ketidakakuratan water meter } \\
& =\frac{\text { Selisih Volume AIr (liter) }}{\text { Jumlah Sampel (liter) }} \times 100 \% \\
& =\frac{1,6}{10 \times 40} \times 100 \% \\
& =0,4 \%
\end{aligned}
$$

Batas ketidakakuratan water meter yang diijinkan adalah sebesar $2 \%$, berdasarkan hasil perhitungan di atas water meter di Zona Kota Blahbatuh masih tergolong baik karena dibawah batas yang diijinkan. Hal ini dikarenakan telah dilakukan pergantian water meter secara berkala oleh PDAM Gianyar. 
Tabel 2. Distribusi dan konsumsi air Zona Kota Blahbatuh

\begin{tabular}{cccccc}
\hline No & Bulan & $\begin{array}{c}\text { Distribusi } \\
\left(\mathbf{m}^{\mathbf{3}}\right)\end{array}$ & $\begin{array}{c}\text { Konsumsi } \\
\left(\mathbf{m}^{\mathbf{3}}\right)\end{array}$ & $\begin{array}{c}\text { Pemeliharaan dan perbaikan } \\
\mathbf{p i p a}\left(\mathbf{m}^{\mathbf{3}}\right)\end{array}$ & $\begin{array}{c}\text { Jumlah } \\
\text { SR }\end{array}$ \\
\hline 1 & Januari & 67.274 & 23.954 & 539,60 & 1.498 \\
2 & Februari & 67.950 & 26.211 & 396,40 & 1.502 \\
3 & Maret & 65.454 & 25.727 & 959,80 & 1.504 \\
4 & April & 15.419 & 23.790 & 48,40 & 1.506 \\
5 & Mei & 54.423 & 35.126 & 381,40 & 1.508 \\
6 & Juni & 69.577 & 26.542 & 166,40 & 1.512 \\
7 & Juli & 69.158 & 28.835 & 189,80 & 1.515 \\
8 & Agustus & 81.031 & 23.132 & 286,00 & 1.565 \\
9 & September & 81.113 & 23.944 & 112,60 & 1.570 \\
10 & Oktober & 77.499 & 24.848 & 721,80 & 1.573 \\
11 & November & 74.858 & 27.091 & 1280,20 & 1.573 \\
12 & Desember & 67.700 & 28.111 & 483,80 & 1.574 \\
& Rata-rata & 65.954 & 26.442 & 463,85 & - \\
\hline
\end{tabular}

Tabel 3. Hasil pengambilan data akurasi meter pelanggan

\begin{tabular}{clrccc}
\hline \multirow{2}{*}{ No } & Nama pelanggan & $\begin{array}{c}\text { Nomor } \text { water } \\
\text { meter }\end{array}$ & \multicolumn{2}{c}{ Volume air yang terbaca (liter) } & Selisih \\
\cline { 3 - 4 } (liter)
\end{tabular}


Tabel 3. Hasil pengambilan data akurasi meter pelanggan (lanjutan)

\begin{tabular}{clrccc}
\hline \multirow{2}{*}{ No } & Nama pelanggan & $\begin{array}{c}\text { Nomor water } \\
\text { meter }\end{array}$ & \multicolumn{2}{c}{ Volume air yang terbaca (liter) } & Selisih \\
\cline { 3 - 5 } (liter)
\end{tabular}

Tabel 4. Hasil perhitungan neraca air

\begin{tabular}{|c|c|c|c|c|}
\hline \multirow{7}{*}{$\begin{array}{l}\text { Volume } \\
\text { input system } \\
=791.453,8 \\
\mathrm{~m}^{3} / \text { tahun } \\
(100 \%)\end{array}$} & \multirow{4}{*}{$\begin{array}{l}\text { Konsumsi } \\
\text { resmi = } \\
322.877,2 \\
\text { m3/tahun } \\
(40,8 \%)\end{array}$} & \multirow{2}{*}{$\begin{array}{l}\text { Konsumsi resmi } \\
\text { berekening = } \\
317.311 \mathrm{~m}^{3} / \text { tahun } \\
(40,09 \%)\end{array}$} & $\begin{array}{l}\text { Konsumsi bermeter berekening }=317.311 \\
\mathrm{~m}^{3} / \operatorname{tahun}(40,09 \%)\end{array}$ & \multirow{2}{*}{$\begin{array}{l}\text { Air } \\
\text { berekening }= \\
317.311 \\
\mathrm{~m}^{3} / \text { tahun } \\
(40,09 \%)\end{array}$} \\
\hline & & & $\begin{array}{l}\text { Konsumsi tak bermeter berekening } \\
\text { (estimasi water meter pelanggan rusak) }\end{array}$ & \\
\hline & & \multirow{2}{*}{$\begin{array}{l}\text { Konsumsi resmi } \\
\text { tak berekening = } \\
5.566,2 \mathrm{~m} 3 / \text { tahun } \\
(0,71 \%)\end{array}$} & $\begin{array}{l}\text { Konsumsi bermeter tak berekening } \\
\text { (pemakaian pada instansi tertentu }\end{array}$ & \multirow{5}{*}{$\begin{array}{l}\text { Air tak } \\
\text { berekening } \\
(\mathrm{NRW})= \\
474.142,83 \\
\mathrm{~m}^{3} / \text { tahun } \\
(59,91 \%)\end{array}$} \\
\hline & & & $\begin{array}{l}\text { Konsumsi tak bermeter tak berekening } \\
\text { (pencucian pipa) } 5.566,2 \mathrm{~m}^{3} / \text { tahun }(0,71 \%)\end{array}$ & \\
\hline & \multirow{3}{*}{$\begin{array}{l}\text { Kehilangan } \\
\text { air }= \\
468.576,63 \\
\mathrm{~m}^{3} / \text { tahun } \\
(59,2 \%)\end{array}$} & \multirow{2}{*}{$\begin{array}{l}\text { Kehilangan air } \\
\text { non fisik }= \\
3.165,82 \\
\mathrm{~m}^{3} / \text { tahun }(0,4 \%)\end{array}$} & $\begin{array}{l}\text { Konsumsi tak resmi (estimasi pencurian } \\
\text { air/sambungan liar) }\end{array}$ & \\
\hline & & & $\begin{array}{l}\text { Ketidakakuratan meter pelanggan } 3.165,82 \\
\mathrm{~m}^{3} / \text { tahun }(0,4 \%)\end{array}$ & \\
\hline & & $\begin{array}{l}\text { Kehilangan air } \\
\text { fisik = } \\
465.410,82 \\
\mathrm{~m}^{3} / \text { tahun }(58,8 \%)\end{array}$ & $\begin{array}{l}\text { Kebocoran pada jaringan, luapan reservoir, } \\
\text { dan kebocoran pipa dinas pelanggan } \\
465.410,82 \mathrm{~m}^{3} / \text { tahun }(58,8 \%)\end{array}$ & \\
\hline
\end{tabular}

Berdasarkan hasil perhitungan di atas, dapat dihitung kehilangan air dari water meter (WM) pelanggan sebagai berikut:

Kehilangan akibat ketidakakuratan WM

= Ketidakakuratan WM x V. Input Sistem

$=0,4 \% \times 65.954,49 \mathrm{~m}^{3} / \mathrm{bulan}$

$=263,82$

$=3.165,82 \mathrm{~m}^{3} /$ tahun

\section{Penyusunan neraca air}

Neraca air dihitung berdasarkan data dan hasil survei di lapangan. Neraca air menunjukan tingkatan ataupun besaran kehilangan air baik fisik maupun non-fisik. Hasil perhitungan neraca air disajikan dalam Tabel 4, yang diperoleh dengan perhitungan berikut:
Menentukan volume input sistem

Volume input sistem merupakan jumlah air yang didistribusi selama satu tahun yang kemudian dirata-ratakan.

Volume Input Sistem

$$
\begin{aligned}
& =65.954,49 \mathrm{~m}^{3} 3 / \text { bulan } \\
& =791.453,8 \mathrm{~m}^{3} / \text { tahun }
\end{aligned}
$$

\section{Menentukan konsumsi resmi}

Konsumsi resmi merupakan jumlah dari konsumsi bermeter berekening dan konsumsi tak bermeter tak berekening. Konsumsi bermeter berekening adalah volume air pada rekening tagihan pelanggan. Sedangkan konsumsi tak bermeter tak berekening adalah volume air yang digunakan untuk kepentingan instansi, pemeliharaan dan perbaikan jaringan. 
Konsumsi bermeter berekening

$=26.442,58 \mathrm{~m}^{3} /$ bulan

$=317.311 \mathrm{~m}^{3} /$ tahun

Konsumsi tak bermeter tak berekening

$=463,85 \mathrm{~m}^{3} / \mathrm{bulan}$

$=5.566,20 \mathrm{~m}^{3} /$ tahun

Konsumsi resmi $=317.311+5.566,20$

$$
=322.877,2
$$

\section{Menghitung kehilangan air}

Kehilangan air $=$ volume input sistem

$$
\begin{aligned}
& - \text { konsumsi resmi } \\
= & 791.453,8-322.877,2 \\
= & 468.576,63 \mathrm{~m}^{3} / \text { tahun }
\end{aligned}
$$

\section{Menentukan kehilangan air non fisik}

Kehilangan air non fisik = ketidakakuratan WM pelanggan $=3.165,82 \mathrm{~m}^{3} /$ tahun

\section{Menentukan kehilangan air fisik}

Kehilangan air fisik = kehilangan air

$$
\begin{aligned}
& - \text { kehilangan non fisik } \\
= & 468.576,63-3.165,82 \\
= & 465.410,82 \mathrm{~m}^{3} / \text { tahun }
\end{aligned}
$$

\section{Menyusun neraca air}

Berdasarkan hasil perhitungan di atas, nilai tiap komponen kemudian dimasukkan pada kolom di tabel neraca air yang disajikan dalam Tabel 4. Sedangkan apabila menggunakan besar NRW sesuai dengan batas toleransi maksimal sebesar $20 \%$, maka hasil yang didapatkan disajikan pada Tabel 5.

\section{Analisis penyebab dan penanggulangan NRW}

Berdasarkan hasil uji step test, uji UFM dan wawancara dengan pegawai PDAM Gianyar bidang transmisi dan distribusi, serta berdasarkan hasil penelitian yang sudah dilakukan Yekti et al. (2019) di zona berbeda, didapat beberapa penyebab dan penanggulangan terjadinya kehilangan air di Zona Kota Blahbatuh yang dijabarkan berurutan sebagai berikut:

Penyebab kehilangan air fisik

- Aksesoris pipa; pada saat dilakukannya step test ditemukan valve 5 mengalami aus. Hal ini menyebabkan pelaksanaan step test yang dilakukan oleh PDAM Gianyar menjadi tidak sempurna karena ruas pipa tidak terisolasi total meyebabkan status ruas pipa yang dianalisis tidak dapat diketahui dengan akurat.

- Pipa bocor; pada ruas pipa 11 step test I, Kebocoran pipa distribusi menjadi salah satu

\begin{tabular}{|c|c|c|c|c|}
\hline \multirow{9}{*}{$\begin{array}{l}\text { Volume } \\
\text { input } \\
\text { sistem = } \\
791.453,8 \\
\mathrm{~m}^{3} / \text { tahun } \\
(100 \%)\end{array}$} & \multirow{6}{*}{$\begin{array}{l}\text { Konsumsi resmi } \\
=638.782,362 \\
\mathrm{~m}^{3} / \mathrm{tahun} \\
(80,71 \%)\end{array}$} & \multirow{2}{*}{$\begin{array}{l}\text { Konsumsi } \\
\text { Resmi } \\
\text { Berekening = } \\
633.216,162 \\
\mathrm{~m}^{3} / \text { tahun } \\
(80 \%) \\
\end{array}$} & $\begin{array}{l}\text { Konsumsi bermeter berekening }= \\
633.216,162 \mathrm{~m}^{3} / \operatorname{tahun}(80 \%)\end{array}$ & \multirow{2}{*}{$\begin{array}{l}\text { Air berekening }= \\
633.216,162 \\
\mathrm{~m}^{3} / \text { tahun } \\
(80 \%)\end{array}$} \\
\hline & & & $\begin{array}{l}\text { Konsumsi tak bermeter } \\
\text { berekening (Estimasi water meter } \\
\text { pelanggan rusak) }\end{array}$ & \\
\hline & & \multirow{4}{*}{$\begin{array}{l}\text { Konsumsi } \\
\text { resmi Tak } \\
\text { Berekening = } \\
5.566,2 \\
\mathrm{~m}^{3} / \text { tahun } \\
(0,71 \%)\end{array}$} & $\begin{array}{l}\text { Konsumsi bermeter tak } \\
\text { berekening (Pemakaian pada }\end{array}$ & \multirow{7}{*}{$\begin{array}{l}\text { Air tak } \\
\text { berekening } \\
(\mathrm{NRW})= \\
158.237,638 \\
\mathrm{~m}^{3} / \text { tahun } \\
(20 \%)\end{array}$} \\
\hline & & & & \\
\hline & & & Konsumsi tak bermeter tak & \\
\hline & & & $\begin{array}{l}\text { berekening (pencucian pipa) } \\
5.566,2 \mathrm{~m}^{3} / \operatorname{tahun}(0,71 \%)\end{array}$ & \\
\hline & \multirow{3}{*}{$\begin{array}{l}\text { Kehilangan air }= \\
152.671,438 \\
\mathrm{~m}^{3} / \text { tahun } \\
(19,29 \%)\end{array}$} & \multirow{2}{*}{$\begin{array}{l}\text { Kehilangan air } \\
\text { non fisik = } \\
3.165,82 \\
\mathrm{~m}^{3} / \text { tahun } \\
(0,4 \%)\end{array}$} & $\begin{array}{l}\text { Konsumsi tak resmi (estimasi } \\
\text { pencurian air/sambungan liar) }\end{array}$ & \\
\hline & & & $\begin{array}{l}\text { Ketidakakuratan meter pelanggan } \\
3.165,82 \mathrm{~m}^{3} / \operatorname{tahun}(0,4 \%)\end{array}$ & \\
\hline & & $\begin{array}{l}\text { Kehilangan air } \\
\text { fisik }= \\
149.505,618 \\
\mathrm{~m}^{3} / \text { tahun } \\
(18,89 \%)\end{array}$ & $\begin{array}{l}\text { Kebocoran pada jaringan, luapan } \\
\text { reservoir, dan kebocoran pipa } \\
\text { dinas pelanggan } 149.505,618 \\
\mathrm{~m}^{3} / \text { tahun }(18,89 \%)\end{array}$ & \\
\hline
\end{tabular}
penyebab kehilangan air.

- Kekuatan pipa; kekuatan pipa erat kaitannya dengan besarnya tekanan yang dapat ditahan oleh pipa yang terpasang di sistem penyediaan air minum Zona Kota Blahbatuh. Seandainya terjadi

Tabel 5. Hasil perhitungan neraca air NRW $20 \%$ 
tekanan yang lebih besar dari tekanan ijin pipa, maka pipa akan berpotensi mengalami retak, pecah, dan putus.

- Usia Jaringan; pada Zona Kota Blahbatuh, usia jaringan pipa yang dimiliki terbilang cukup lama. Hal ini menyebabkan pipa rentan mengalami kerusakan seperti pecah, retak dan aus bahkan putus.

Penyebab kehilangan air non fisik

- Akurasi water meter; ketidakakuratan water meter dapat menjadi penyebab dalam menyumbang besarnya kehilangan air yang terjadi di Zona Kota Blahbatuh.

- Ketersediaan peralatan; ketersediaan peralatan yang dimaksud yaitu tidak seimbangnya jumlah alat yang tersedia dengan jumlah zona yang ada.

- Kesalahan administrasi; kesalahan administrasi yang sering terjadi yaitu pada pencatatan dan pembacaan water meter induk dan water meter pelanggan tidak sesuai dengan jadwal yang seharusnya.

- Sumber daya manusia; pada zona pelayanan yang terdapat di PDAM Gianyar, sebanyak 51 zona hanya terdapat 3 pegawai yang membidangi NRW sedangkan pada setiap zona tidak luput dari kehilangan air.

\section{Penanggulangan kehilangan air fisik}

- Pembentukan DMA; apabila DMA yang terpasang mampu bekerja dengan optimal maka analisis kehilangan air dapat dilakukan dengan teliti karena ruang lingkup analisis menjadi lebih sempit.
- Penggantian aksesoris pipa; pemeriksaan aksesoris pipa secara berkala dapat meminimalisir kehilangan air yang terjadi.

- Pemeliharaan jaringan pipa; pemeliharaan jaringan pipa bertujuan untuk mengganti pipapipa yang retak, pecah, bocor maupun putus agar kehilangan air tidak semakin sering terjadi dan besarnya NRW dapat diminimalisir.

- Mempercepat waktu perbaikan; semakin cepat kehilangan air diketahui dan ditanggulangi maka kehilangan air yang terjadi akan semakin kecil.

- Pengendalian tekanan; pengendalian tekanan bertujuan untuk meminimalisir kehilangan air yang terjadi karena besarnya tekanan berbanding lusur dengan besarnya kehilangan air yang terjadi.

Penanggulangan kehilangan air non fisik

- Kalibrasi dan penggantian water meter; kalibrasi water meter dilakukan guna mengetahui keakuratan water meter pelanggan ataupun water meter induk.

- Pelatihan untuk pegawai; pelatihan diperlukan untuk meningkatkan pengetahuan pegawai tentang NRW, pemasangan alat serta pemakaian alat.

- Pemberian sanksi; sanksi yang diberikan dapat berupa pencabutan sambungan dan pemberian denda bagi pelaku tindakan illegal.

- Survei rumah ke rumah; survei rumah ke rumah bertujuan untuk menyelidiki terjadinya pencurian air atau pemasangan pipa illegal. Selain itu juga survei ini memberikan kesan positif antara pihak penyedia jasa dan pengguna jasa.

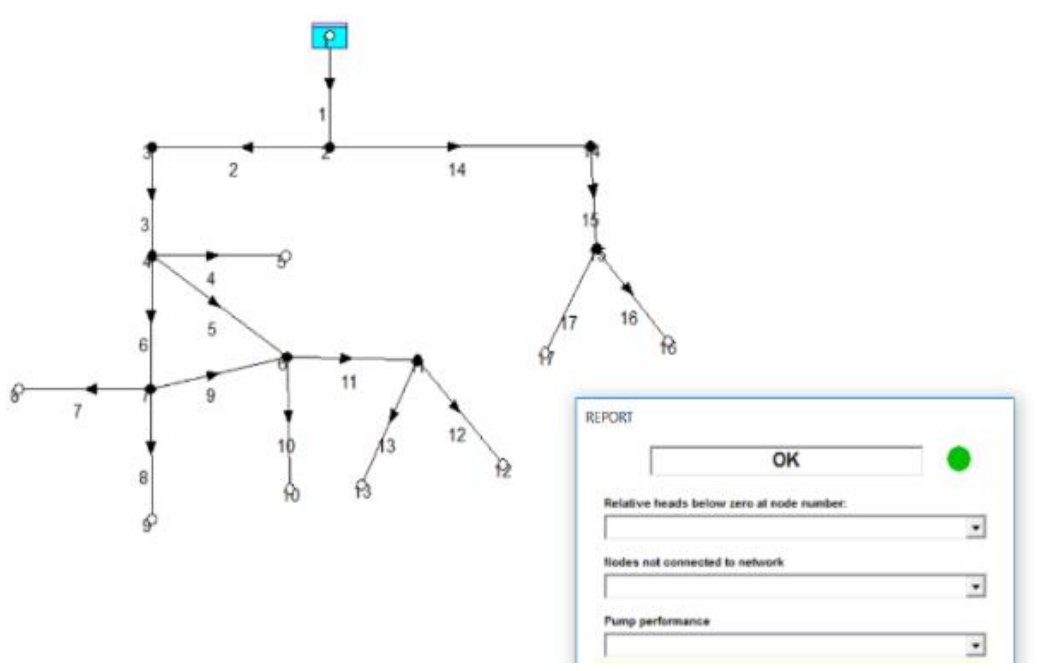

Gambar 3. Skema jaringan pipa DMA Pande alternatif 3 


\section{Evaluasi jaringan distribusi}

Dalam mengevaluasi jaringan distribusi digunakan program bantu berupa WaterNet. Sistem jaringan distribusi yang dipakai adalah jaringan distribusi di dalam DMA Pande dengan jumlah sambungan yaitu 619 SR. Evaluasi ini dilakukan dengan menggunakan tiga alternatif yaitu; alternatif 1 dan alternatif 2 dengan debit 8,8 liter/dt dan debit 3,51 liter/dt yang didapat dari laporan teknik PDAM Gianyar 2018 serta alternatif 3 dengan debit optimum sesuai dengan batas maksimal NRW sebesar 20\% yang diperoleh dari perhitungan dengan besar debit adalah 4,375 liter/dt. Spesifikasi alternatif 3 disajikan dalam Tabel 6, Tabel 7 dan Gambar 3

Tabel 6. Data node alternatif 3

\begin{tabular}{ccccc}
\hline Titik & $\begin{array}{c}\text { Enersi } \\
\text { dasar } \\
(\mathbf{m})\end{array}$ & $\begin{array}{c}\text { Enersi } \\
\text { absolut } \\
(\mathbf{m})\end{array}$ & $\begin{array}{c}\text { Enersi } \\
\text { relatif } \\
(\mathbf{m})\end{array}$ & $\begin{array}{c}\text { Konsumsi } \\
(\mathbf{l} / \mathbf{d})\end{array}$ \\
\hline 1 & 131 & 138,50 & 7,50 & 0,00 \\
2 & 115 & 131,54 & 16,54 & 0,00 \\
3 & 105 & 129,00 & 24,00 & 0,00 \\
4 & 103 & 128,56 & 25,56 & 0,03 \\
5 & 102 & 128,39 & 26,39 & 0,11 \\
6 & 102 & 125,18 & 23,18 & 0,90 \\
7 & 101 & 128,10 & 27,10 & 0,30 \\
8 & 98 & 127,46 & 29,46 & 0,29 \\
9 & 98 & 128,09 & 30,09 & 0,20 \\
10 & 92 & 124,92 & 32,92 & 0,17 \\
11 & 100 & 122,63 & 22,63 & 1,38 \\
12 & 85 & 122,62 & 37,62 & 0,06 \\
13 & 89 & 121,40 & 32,40 & 0,47 \\
14 & 100 & 131,52 & 31,52 & 0,00 \\
15 & 99 & 131,34 & 32,34 & 0,00 \\
16 & 85 & 131,07 & 46,07 & 0,46 \\
17 & 89 & 131,34 & 42,34 & 0,00 \\
\hline
\end{tabular}

Berdasarkan hasil evaluasi yang telah dilakukan, maka pada kondisi eksisting yang ada di DMA Pande untuk alternatif 1 didapat besar NRW yang terjadi adalah sebesar 59,9\% dengan kondisi jaringan belum bekerja secara optimal. Sedangkan untuk alternatif 2 dan 3 didapat besar NRW sebesar $0,3 \%$ dan $20 \%$ dengan kondisi jaringan yang dapat bekerja secara optimal dan untuk alternatif 3 dengan debit sebesar 4,375 liter/detik masih bisa digunakan karena masih berada pada batas maksimal toleransi NRW yaitu sebesar $20 \%$ seperti yang terlihat pada gambar di atas. Akan tetapi semua itu tidak lepas dari kenyataan bahwa pada lampiran uji step test, jumlah SR di DMA Pande sebesar 619 SR belum memenuhi syarat optimal terbentuknya suatu DMA yaitu antara 1000-2500 SR.
Tabel 7. Data pipa dan aliran alternatif 3

\begin{tabular}{crccccc}
\hline $\begin{array}{c}\text { No. } \\
\text { pipa }\end{array}$ & $\begin{array}{c}\text { Lpipa } \\
(\mathbf{m})\end{array}$ & $\begin{array}{c}\mathbf{D}_{\text {pipa }} \\
(\mathbf{m})\end{array}$ & $\begin{array}{c}\mathbf{Q} \\
(\mathbf{l} / \mathbf{d})\end{array}$ & $\begin{array}{c}\text { De } \\
(\mathbf{m})\end{array}$ & $\begin{array}{c}\mathbf{h f} \\
(\mathbf{m})\end{array}$ & $\mathbf{i}$ \\
\hline 1 & 2103 & 0,100 & 4,38 & 0,015 & 6,96 & 0,0033 \\
2 & 939 & 0,100 & 3,92 & 0,015 & 2,55 & 0,0027 \\
3 & 160 & 0,100 & 3,92 & 0,015 & 0,43 & 0,0027 \\
4 & 390 & 0,040 & 0,11 & 0,015 & 0,17 & 0,0004 \\
5 & 985 & 0,050 & 0,69 & 0,015 & 3,38 & 0,0034 \\
6 & 265 & 0,100 & 3,09 & 0,015 & 0,47 & 0,0018 \\
7 & 290 & 0,040 & 0,29 & 0,015 & 0,64 & 0,0022 \\
8 & 250 & 0,100 & 0,21 & 0,015 & - & - \\
9 & 705 & 0,075 & 2,29 & 0,015 & 2,91 & 0,0041 \\
10 & 302 & 0,040 & 0,17 & 0,015 & 0,26 & 0,0009 \\
11 & 848 & 0,075 & 1,92 & 0,015 & 2,55 & 0,0030 \\
12 & 1074 & 0,075 & 0,06 & 0,015 & 0,01 & - \\
13 & 690 & 0,050 & 0,47 & 0,015 & 1,23 & 0,0018 \\
14 & 389 & 0,100 & 0,46 & 0,015 & 0,02 & 0,0001 \\
15 & 747 & 0,075 & 0,46 & 0,015 & 0,18 & 0,0002 \\
16 & 1074 & 0,075 & 0,46 & 0,015 & 0,26 & 0,0002 \\
17 & 356 & 0,050 & - & 0,015 & - & - \\
\hline
\end{tabular}

\section{Kesimpulan}

Berdasarkan hasil penelitian dan pembahasan analisis non revenue water dalam district meter area dapat disimpulkan bahwa besarnya NRW yang terjadi di Zona Kota Blahbatuh adalah sebesar $474.142,83 \mathrm{~m}^{3} /$ tahun $(59,91 \%)$ dengan tingkat kehilangan air $468.576,63 \mathrm{~m}^{3} /$ tahun $(59,2 \%)$ yang terdiri dari kehilangan air fisik sebesar $465.410,82$ $\mathrm{m}^{3} /$ tahun $(58,8 \%)$ dan kehilangan air non fisik sebesar 3.165,82 $\mathrm{m}^{3} /$ tahun $(0,4 \%)$. Besarnya NRW yang terjadi di tahun 2018 lebih besar dari tahun 2017 yaitu $59,91 \%>59,44 \%$.

Penyebab kehilangan air di Zona Kota Blahbatuh dapat dikelompokkan menjadi dua yaitu penyebab kehilangan air fisik dan non fisik. Kehilangan air fisik disebabkan oleh rusaknya aksesoris pipa, pipa bocor, usia jaringan dan kekuatan pipa. Sedangkan kehilangan air non fisik disebabkan oleh ketidakakuratan akurasi water meter, ketersediaan peralatan, kesalahan administrasi, dan sumber daya manusia.

Penanggulangan yang dapat dilakukan untuk mengurangi besarnya NRW harus dilaksanakan sesuai dengan jenis kehilangan air yang terjadi. Kehilangan air fisik dapat ditanggulangi dengan beberapa cara yaitu dengan melakukan pembentukan DMA, penggantian aksesoris pipa, pemeliharaan jaringan pipa, dan mempercepat waktu perbaikan serta mengendalikan tekanan. Sedangkan kehilangan air non fisik dapat 
ditanggulangi dengan cara melakukan kalibrasi dan penggantian water meter, memberikan pelatihan untuk pegawai, memberikan sanksi bagi pelaku tindakan illegal dan melakukan survei rumah ke rumah. Berdasarkan hasil evaluasi, kondisi eksisting jaringan distribusi di DMA Pande belum bekerja secara optimal. Hal itu dilihat dari hasil WaterNet dan dari jumlah SR yang belum memenuhi syarat terbentuknya suatu DMA.

\section{Saran}

Berdasarkan hasil penelitian yang telah dilakukan, beberapa saran yang dapat diberikan yaitu sebaiknya PDAM Gianyar melakukan penyelidikan terhadap kemungkinan kehilangan air non fisik untuk mengurangi tingkat kehilangan air demi pelayanan yang lebih baik, meninjau komponen jaringan yang sudah berusia tua serta melakukan perbaikan terhadap perpipaan yang mengalami kerusakan untuk menurunkan tingkat kebocoran yang terjadi, meningkatkan kecepatan dalam mengetahui ruas pipa yang berpotensi mengalami kehilangn air agar titik kehilangan air cepat ditemukan sehingga kerugian dan NRW yang terjadi dapat diminimalisir, membentuk DMA sesuai dengan syarat pembentukan suatu DMA seperti jumlah SR antara 1000-2500 SR tiap DMA yang ada serta untuk penelitian selanjutnya, sebaiknya dilakukan evaluasi jaringan pada setiap DMA yang ada agar dapat diperhitungkan dengan maksimal.

\section{Daftar Pustaka}

Annisa, A, N., \& Hadi, W. (2015). Studi iteratur Perencanaan dan Algoritma Pembentukan DMA (District Meter Area). Jurnal Teknik ITS, 4, 2337 3539.

BPPSPAM. (2014). Laporan Kinerja PDAM 2014.

BRPAM DKI Jakarta. (2014). Laporan kinerja badan regulator PAM DKI Jakarta 2014. Jakarta

Departemen Pekerjaan Umum BPPSPAM. (2014). Pedoman penurunan air tak berekening (non revenue water). Jakarta: BPPSPAM - Kementerian Pekerjaan Umum.

Dewi, K. H., Koosdaryani, K. \& Muttaqien, A. Y. (2015). Analisis Kehilangan Air Pada Pipa Jaringan Distribusi Air Bersih PDAM Kecamatan Baki, Kabupaten Sukoharjo. Jurnal Matriks Teknik Sipil.

Dighade, R. R., Kadu, M. \& Pande, A. M. (2015). Non Revenue Water Reduction Strategy in Urban Water Supply System in India. International Journal of Research in Engineering and Applied Sciences, 3(1), 17-24
Farley, M., Wyeth, G., Ghazali, Z., B. M., Istandar, A. \& Gingh, S. (2008). The manager's non-revenue water handbook. A Guide to Understanding Water Losses, 110.

Febriany, I. E. (2014). Strategi penurunan kebocoran di sistem distribusi air bersih Kota Mataram. Institut Teknologi Sepuluh Nopember. Surabaya.

Frauendorfer, R. \& Liemberger, R. (2010). The issues and challenge of reducing non-revenue water. Mandaluyong: Asian Development Bank.

Imsawan el-Ahmady, I. \& Sembiring, E. (2014). Pemilihan Program Pengendalian Kehilangan Air Serta Pengaruh Implementasinya Terhadap Peningkatan Pendapatan PDAM. Jurnal Teknik Lingkungan, 20(2), 142- 151.

KEMENTERIAN-PUPR. (2016). Panduan pendampingan sistem penyediaan air Minum (SPAM) perpipaan berbasis masyarakat. Jakarta.

PDAM. (2018). Laporan teknik PDAM Gianyar. Gianyar.

Putra, J. P. N. (2009). Studi kehilangan air pada jaringan distribusi PDAM di jalan Soekarno - Hatta Palembang dengan metode DMA (District Meter Area). Politeknik Negeri Sriwijaya.

Rinaldi, A. (2016). Modul perhitungan neraca air “studi kasus Kota Cirebon". Fakultas Ilmu dan Teknologi Kebumian (FITB). Institut Teknologi Bandung.

Sembiring, E. P. K. (2017). Analisis kehilangan air fisik PDAM Tirtanadi Sunggal pada wilayah pelayanan Kompleks Graha Sunggal. Program Studi Teknik Sipil Fakultas Teknik Universitas Sumatra Utara.

Syahputra, B. (2015). Modul waternet. https://www.scribd.com/doc/223468058/Modul-

Waternet

Tanjung, Z. (2013). Kajian kehilangan air pada wilayah pelayanan PDAM (Tirta Nauli) Sibolga. Program Studi Teknik Lingkungan Fakultas Teknik Universitas Sumatera Utara.

Yekti, M. I., Norken, I N., \& Wentiari, N. P. R. (2019). Non-Revenue Water (NRW) and its handling for a drinking water supply system in Kedewatan zone Gianyar Bali. MATEC Web Conference Volume 276. Retrieved from https://doi.org/10.1051/matecconf/201927604004 